\title{
Polyurethane as an Isolation for Covered Conductors
}

Žiga Voršič

Additional information is available at the end of the chapter

http://dx.doi.org/10.5772/35083

\section{Introduction}

The designers of electro energetic system are thinking, to conserve the routes of $220 \mathrm{kV}$ transmission lines, and the transition to $400 \mathrm{kV}$ lines. The easiest way seems to be the placement of new overhead power lines. The other option is the use of covered conductors. Covered conductors are conductors with insulation made from two dielectrics: the first is the insulation mantel and the other is air. The covered conductors consist of a conductor which is a metal electrode (a cable), and the covering mantel which is made from a dielectric with a greater dielectric constant and higher breakdown voltage. The other dielectric with a lower dielectric constant is the surrounding air. The conductor should not be touched despite the insulation.

According to the usual labelling of conductors, we named the suggested conductor PUAC $2150 / 490 / 65 \mathrm{~mm}^{2}$. Here $2150 \mathrm{~mm}^{2}$ stands for the cross section of the polyurethane mantel, $490 \mathrm{~mm}^{2}$ for the aluminium and $65 \mathrm{~mm}^{2}$ for the core made from carbon fibbers. The saved weight (instead of steel we use carbon fibbers) can be used for the insulation. The insulation has to be thick enough so that the electric field intensity on the edge of the insulator does not exceed the critical electric field intensity of air. Such a conductor, hanged on a typical $220 \mathrm{kV}$ transmission tower meets the electric load exerted. Simplified analytical calculations of the electric field intensity on the edge of the insulation match exact calculation, using the finite element method. This fact encourages new research, both theoretical and practical.

\section{The current usage of covered conductors in the middle to high voltage networks}

Covered conductors for overhead power lines are meant to replace the existing bare cable power lines, especially in wooden areas where the risk of falling trees is high. Another concern is the weighing down of cables from sticking snow and ice. Reasons for using 
covered conductors are better safety, ecology (fewer disturbances in the nature, especially less clearing of trees), better operational reliability and lower operating costs.

\subsection{Covered conductors}

The most widespread structure of covered conductors consists of the core made from hard, compact aluminium alloy and a watertight/waterproof mantel made from a cross-linked polyethylene (XLPE). The use has shown the reliability of this type of conductor in very difficult conditions. It will withstand the weight of a fallen tree for days, mechanically and electrically.

Because of the outer mantel, the covered conductors are not that vulnerable when touching each other, or in contact with tree branches. This enables the spacing between phases/cables to shrink to one third of the space between normal over ground power lines. The platform for an over ground power line in a wooden area can therefore be smaller/narrower.

\subsection{The use of covered conductors}

Slovenia began to introduce covered conductors in 1992. In the same year Elektro Gorenjska performed reconstruction of the transmission line Savica - Komna, where they replaced the bare conductors with covered ones. All other parts of the power lines stayed the same. In the year 1939, Elektro Ljubljana build the first power line based on finish technology. They decided for the finish $20 \mathrm{kV}$ system because of positive experience from a more than $10000 \mathrm{~km}$ of build power lines with covered conductors. These experiences show us that the use of such system reliability has increased by 5 times. The number of failures per year on a $100 \mathrm{~km}$ long section is 4.5 for bare conductors and 0.9 for covered conductors in the SN network (Tičar I., Zorič T., 2003). Because the two mentioned power lines successfully passed the adverse weather conditions (sleet, an additional burden of winter), the importer and representative (C\&G d.o.o. Ljubljana) for the company (Ensto), obtain an expert opinion on the imported equipment. It was found that the covered conductors, the corresponding hanging and insulation materials and the overvoltage protection used in the $20 \mathrm{kV}$ distribution network conform to the current JUS standard. The material and equipment that is not included in the JUS standard was covered and conformed in the international IEC standards.

\subsection{High voltage}

In the Scandinavian countries, the development of overhead lines that use covered conductors began in the mid-eighties. The first country to introduce covered conductors was Finland. The finish distribution company FingridOjv with the cooperation of Eltel Networks began with the use of covered conductor in high voltage networks. They build a $110 \mathrm{kV}$ DV power line Mätäkivi-Sula with a length of $6 \mathrm{~km}$, half of which was equipped with covered conductors. In the construction of the transmission lines, composite insulators were used.

In General Public Utilities/ Pennsylvania Electric Company they researched the electric and mechanic effects of covered conductors insulated with polyethylene. Those cables had high specific weight and were installed on several insulators and clamps. They conducted two 
experiments with the voltage of $70 \mathrm{kV}$. The first was to determine the feasibility of the existent spacer (a device for spacing bundled conductors). The second was done on a distribution cable with higher voltage, to determine the criteria for building new compact high-voltage transmission lines in small corridors, especially in densely populated areas.

Since 1980, the use of covered conductors increased worldwide. The reason for this is that the covered conductors are more compact and environmentally friendlier than traditional non-insulated conductors. Also the number of failures is much lower. This development has also an impact on the characteristics of voltage drops and is an important aspect of working with clients, sensitive to such decrease in voltage.

\section{Using covered conductors at the highest voltage levels}

The space around an electrically charged body is in a special state. This special state acts only on particles that have an electric charge. If we introduce a small electric charge that does not significantly alter the state of that space, we find that there is force acting on that small charge. This force is proportional to the electric charge $q$ and the vector quantity that defines the state of the space. It is denoted as $E$. The vector $E$ of the electric field intensity has the same direction as the force.

\subsection{The electric field: Cylinder of charge}

For the understanding of the distribution of voltage and electric field intensity in a covered conductor, we first look at the electric field in a cylinder of charge (Voršič J., Pihler J., 2005). The electric field intensity $E(r)$ of an isolated cylindrical Gaussian surface is shown in figure 1 .

In an infinitely long charged cylinder two things are true:

a. the electric charge is evenly distributed over the surface of the cylinder,

b. the electrostatic field is a flat radial field.

From the equation,

$$
Q=q \cdot l=D \cdot 2 \cdot \pi \cdot r \cdot l,
$$

where:

$q$-is the electric charge, gathered on the length of the cylinder,

$r$ - is the radius of the equipotential surface,

$l-$ is the length of the cylinder,

$D$-is the electric displacement field and

$Q-$ is the electric charge;

we obtain the absolute value for the electric displacement field,

$$
D=\frac{Q}{A}=\frac{q \cdot l}{2 \cdot \pi \cdot r \cdot l}=\frac{q}{2 \cdot \pi \cdot r}
$$


And it's vector quantity

$$
\vec{D}=D \cdot \overrightarrow{1}_{\mathrm{r}}=\frac{q}{2 \cdot \pi \cdot r} \cdot \overrightarrow{1}_{\mathrm{r}}
$$

The corresponding electric field intensity is

$$
\vec{E}=\frac{\vec{D}}{\varepsilon}=\frac{q}{2 \cdot \pi \cdot \varepsilon \cdot r} \cdot \overrightarrow{1}_{\mathrm{r}}
$$

The Electric potential $V(r)$ on an equipotential surface (concentric cylinder) with a radius $r$ is

$$
V(r)=\int_{r}^{r_{0}} E \cdot \mathrm{d} r=\frac{q}{2 \cdot \pi \cdot \varepsilon} \cdot \int_{r}^{r_{0}} \frac{\mathrm{d} r}{r}=\frac{q}{2 \cdot \pi \cdot \varepsilon} \cdot \ln \frac{r_{0}}{r},
$$

where $r_{0}$ is the radius of the equipotential surface, on which we chose the potential s starting point. Because we assume that the cylinder is infinitely long, we cannot select the starting point of the potential to be in infinity.
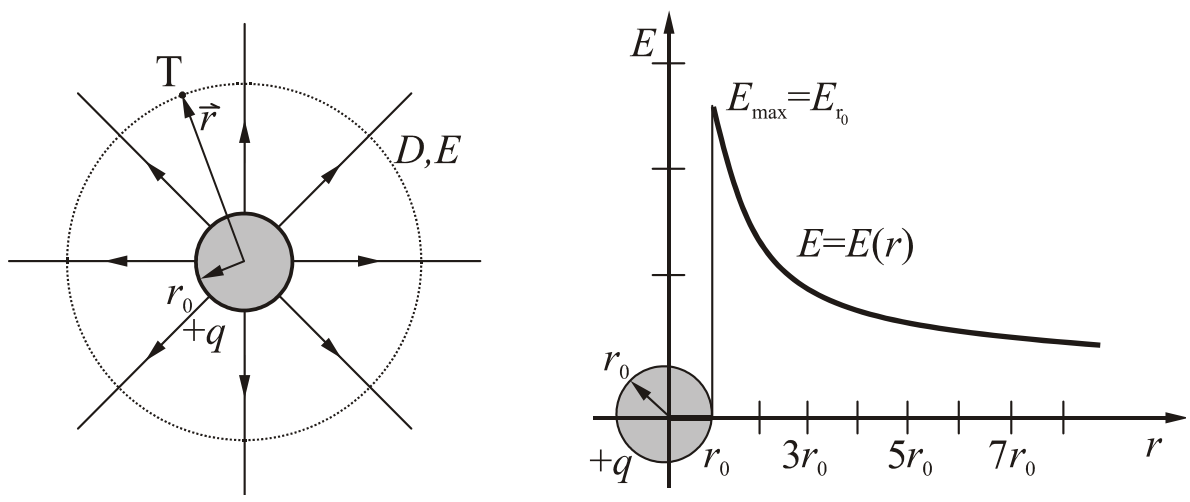

Figure 1. Electric field intensity $E(r)$ of an isolated cylindrical Gaussian surface

Between two equipotential surfaces with the radius $r_{1}$ and $r_{2}$ there is a potential difference

$$
U_{12}=U=V_{1}-V_{2}=\frac{q}{2 \cdot \pi \cdot \varepsilon} \cdot \ln \frac{r_{2}}{r_{1}}
$$

Two concentric cylinders with the length $l$, radius $r_{1}$ and $r_{2}$ and a dielectric between them they form a cylindrical capacitor with the capacitance

$$
C=\frac{Q}{U}=\frac{q \cdot l}{U}=\frac{2 \cdot \pi \cdot \varepsilon \cdot l}{\ln \frac{r_{2}}{r_{1}}}
$$

Because we don't know the exact electric charge, but only the charge between the electrodes, we denote the expression for the electric field intensity at any random point between the two cylindrical electrodes (figure 2) in the form of 


$$
E(r)=\frac{U}{r \cdot \ln \frac{r_{2}}{r_{1}}}
$$

We get the highest value of the electric field intensity on the surface of the inner cylinder.

$$
E\left(r_{1}\right)=\frac{U}{r_{1} \cdot \ln \frac{r_{2}}{r_{1}}}=E_{\max }
$$

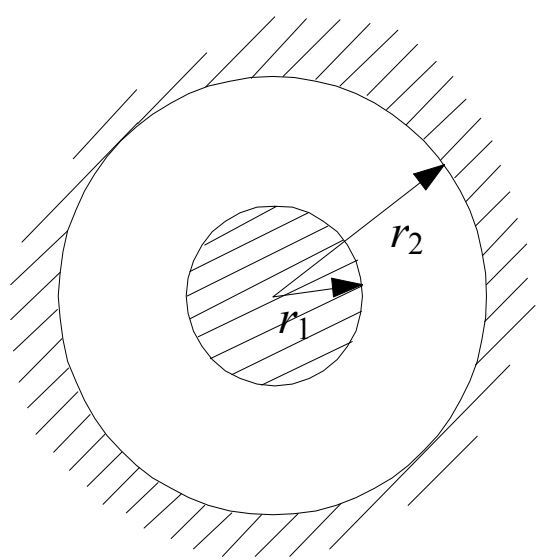

Figure 2. The electric field of two concentric cylinders

\subsection{Double-layer single-wire cable}

The double-layer single-wire cable (figure 3) is a typical example of the use of double-layer dielectrics. The voltage between the core of the cable and the mantel is distributed over the layers of the dielectric.

$$
\begin{gathered}
U_{1}=\frac{q}{2 \cdot \pi \cdot \varepsilon_{0} \cdot \varepsilon_{\mathrm{r} 1}} \cdot \ln \frac{r_{2}}{r_{1}} \\
U_{2}=\frac{q}{2 \cdot \pi \cdot \varepsilon_{0} \cdot \varepsilon_{\mathrm{r} 2}} \cdot \ln \frac{r_{3}}{r_{2}} \\
U=U_{1}+U_{2} \\
U=\frac{q}{2 \cdot \pi \cdot \varepsilon_{0}}\left(\frac{1}{\varepsilon_{\mathrm{r} 1}} \cdot \ln \frac{r_{2}}{r_{1}}+\frac{1}{\varepsilon_{\mathrm{r} 2}} \cdot \ln \frac{r_{3}}{r_{2}}\right)
\end{gathered}
$$




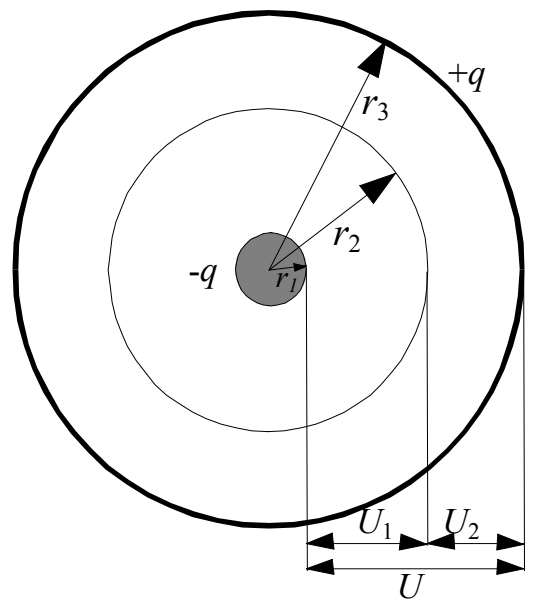

Figure 3. A double-layer single-wire cable

We calculate the electric charge and then both voltage levels.

$$
U_{1}=\frac{U \cdot \ln \frac{r_{2}}{r_{1}}}{\varepsilon_{\mathrm{r} 1} \cdot\left(\frac{1}{\varepsilon_{\mathrm{r} 1}} \cdot \ln \frac{r_{2}}{r_{1}}+\frac{1}{\varepsilon_{\mathrm{r} 2}} \cdot \ln \frac{r_{3}}{r_{2}}\right)}
$$

We get the highest electric field intensity in material 1 at the radius $r_{1}$,

$$
E_{1 \max }=\frac{q}{2 \cdot \pi \cdot \varepsilon_{0} \cdot \varepsilon_{\mathrm{r} 1}} \cdot \frac{1}{r_{1}}=\frac{U \cdot \frac{1}{r_{1}}}{\varepsilon_{\mathrm{r} 1} \cdot\left(\frac{1}{\varepsilon_{\mathrm{r} 1}} \cdot \ln \frac{r_{2}}{r_{1}}+\frac{1}{\varepsilon_{\mathrm{r} 2}} \cdot \ln \frac{r_{3}}{r_{2}}\right)} .
$$

and the highest electric field intensity in material 2 at the radius $r_{2}$

$$
E_{2 \max }=\frac{q}{2 \cdot \pi \cdot \varepsilon_{0} \cdot \varepsilon_{\mathrm{r} 2}} \cdot \frac{1}{r_{2}}=\frac{U \cdot \frac{1}{r_{2}}}{\varepsilon_{\mathrm{r} 2} \cdot\left(\frac{1}{\varepsilon_{\mathrm{r} 1}} \cdot \ln \frac{r_{2}}{r_{1}}+\frac{1}{\varepsilon_{\mathrm{r} 2}} \cdot \ln \frac{r_{3}}{r_{2}}\right)} .
$$




\subsection{Polarized conductors and the electric field intensity}

A covered conductor can be regarded as a two layered insulated conductor. In this case the inner electrode is insulated and the space to the outer electrode is air. The insulation has a much higher dielectric strength than air. Because of that, it is irrelevant that the electric field intensity is small on the inner electrode (figure 4). The important thing is that the electric field intensity in the air is as small as possible: $E_{\text {air }}=E_{2}\left(r_{2}\right)$.

Symbols in figure represent:

$r_{1}$-the radius of the core,

$r_{2}$-the radius of the mantel,

$r_{3}$-the radius of insulation,

$E_{2}-$ the electric field intensity of air.

Taking into account that $\varepsilon_{\mathrm{r} 1}=\varepsilon_{\mathrm{r}}$ and $\varepsilon_{\mathrm{r} 2}=1$ in the equation (20), we get:

$$
E_{2}=\frac{U}{r_{2} \cdot\left(\frac{\ln \frac{r_{2}}{r_{1}}}{\varepsilon_{\mathrm{r}}}+\frac{\ln \frac{r_{3}}{r_{2}}}{1}\right)}
$$

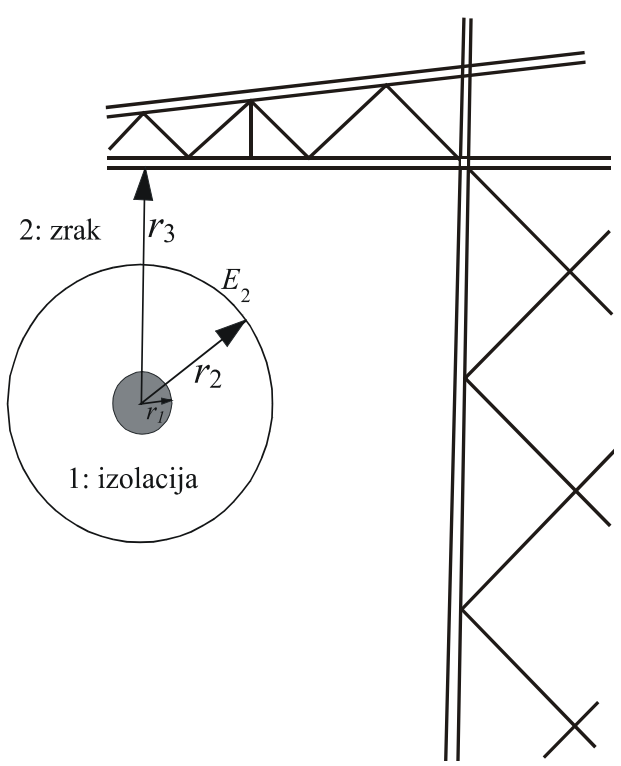

Figure 4. Coaxial cylindrical arrangement of partial isolation

We get the minimum field intensity $E_{2}$ as a function of $r_{2}$, when the denominator in equation (18) is at its highest value (Beyer M., 1986). When we denote the denominator with y and the variable $r_{2}$ as $x$ we derive the function $y(x)$ from $x$. 
Denominator:

$$
y(x)=\left(\frac{\ln \frac{x}{r_{1}}}{\varepsilon_{\mathrm{r}}}+\frac{\ln \frac{r_{3}}{x}}{1}\right)=x \cdot\left(\frac{1}{\varepsilon_{r}} \cdot \ln \frac{x}{r_{1}}-\ln \frac{x}{r_{3}}\right)=\frac{x}{\varepsilon_{r}} \cdot\left(\ln \frac{x}{r_{1}}-\varepsilon_{r} \cdot \ln \frac{x}{r_{3}}\right)
$$

We find the maximum value of the denominator and get the optimal value of the radius,

$$
r_{2 \mathrm{opt}}=r_{1} \cdot \frac{1}{\mathrm{e}} \cdot\left(\frac{r_{3}}{r_{1}}\right)^{\frac{\varepsilon_{r}}{\varepsilon_{r}-1}}
$$

where the electric field intensity in the air is at its smallest value.

$$
E_{2}=E_{2 \min }=\frac{U \cdot \mathrm{e}}{r_{1} \cdot\left(\frac{r_{3}}{r_{1}}\right)^{\frac{\varepsilon_{r}}{\varepsilon_{r}-1}} \cdot\left(1-\frac{1}{\varepsilon_{\mathrm{r}}}\right)}
$$

With the transmission tower, the chain of insulators (the vertical string of discs, $1=2.25 \mathrm{~m}$ ) and the cable $(490 / 65 \mathrm{Al} / \mathrm{Fe}, \mathrm{r}=15.3 \mathrm{~mm})$ of the existing $220 \mathrm{kV}$ over ground power line (Figure 5) the geometry is already set. The only remaining variable is the relative permittivity. If we attempt to calculate the relative permittivity of polyurethane $\left(\varepsilon_{\mathrm{r}}=3.4\right)$, we get the optimal radius where the electric field intensity in the surrounding air is at its smallest value:

$$
r_{2 \mathrm{opt}}=r_{1} \cdot \frac{1}{\mathrm{e}} \cdot\left(\frac{r_{3}}{r_{1}}\right)^{\frac{\varepsilon_{r}}{\varepsilon_{r}-1}}=0,0153 \cdot \frac{1}{2,71828} \cdot\left(\frac{2,25}{0,0153}\right)^{\frac{3,4}{3,4-1}}=6,62 \mathrm{~m}
$$

But this is unrealistic. This is why we try to use other materials with higher values of relative permittivity. Figure 6 shows the dependence of the optimal radius (equation 20) from the relative permittivity. Despite the clear advantages of materials with larger values of relative permittivity we try to use polyurethane.

If we use the same radius as the radius in the current $220 \mathrm{kV}$ overhead conductor $(\mathrm{r}=15.3 \mathrm{~mm})$, the relative permittivity $\varepsilon_{\mathrm{r}}=3.4$ and an insulation that is $15 \mathrm{~mm}$ thick, together with the voltage of $400 \mathrm{kV}$, we get:

$$
E_{\text {air }}=\frac{U}{r_{2} \cdot \varepsilon_{r 2} \cdot\left(\frac{1}{\varepsilon_{r 1}} \cdot \ln \frac{r_{2}}{r_{1}}+\frac{1}{\varepsilon_{r 2}} \cdot \ln \frac{r_{3}}{r_{2}}\right)}=2,39 \mathrm{MV} / \mathrm{m}
$$

The value is smaller from the Dielectric Strength of air in normal conditions (3 MV/m). 


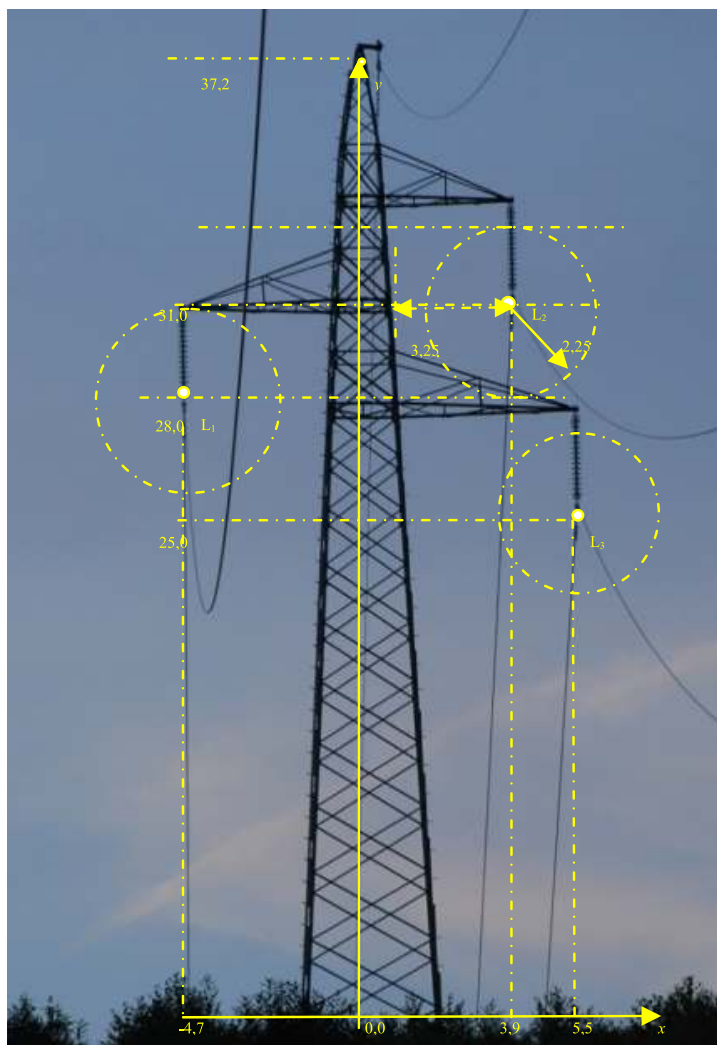

Figure 5. The sketch of a typical $220 \mathrm{kV}$ transmission tower for an overhead power line

The optimal radius of the insulation depending on the relative permittivity

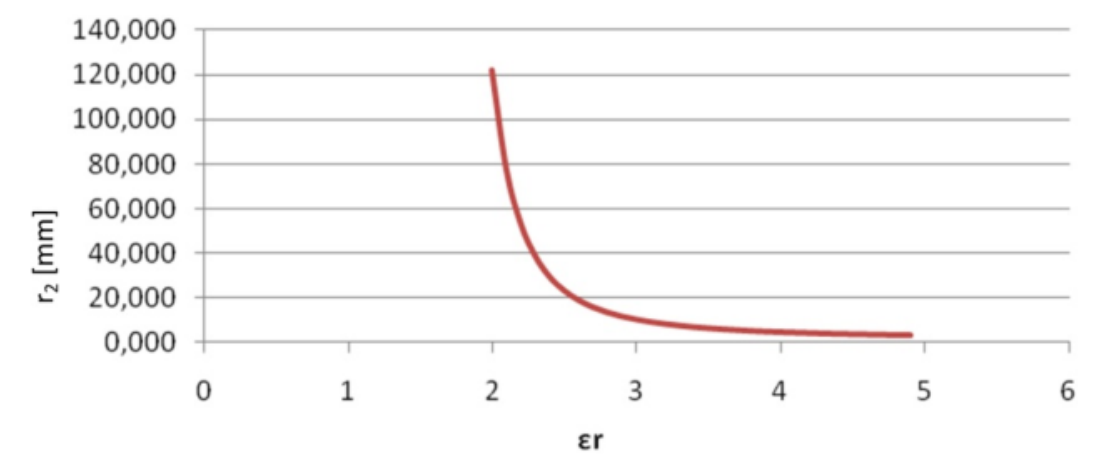

Figure 6. The optimal radius of the insulation depending on the relative permittivity 
For other insulation thicknesses, the electric field intensity (according to equation 21) is shown in figure 7. Figure 8 shows the highest electric field intensities on the edge of the insulation for different values of relative permittivity. The difference becomes apparent only at greater thicknesses of the mantel. You can also see that better dielectric displace more electric field in the worse dielectric - the air.

Figure 9 shows the electric field intensity at the edge of the conductor as the function of the insulation thickness. As expected it is substantially lower than the dielectric strength, the reason being that the majority of the electric field is displaced into the worse dielectric the surrounding which is also more abundant (the length of the string of insulating discs).

According to survey results, we find that the use of covered conductors with insulation made from polyurethane enables the preservation of the existing $220 \mathrm{kV}$ power line platforms and the transition to $400 \mathrm{kV}$ power lines. Furthermore we decided to reduce the weight by using the thinnest possible insulation that still meets all requirements - thickness of $15 \mathrm{~mm}$.

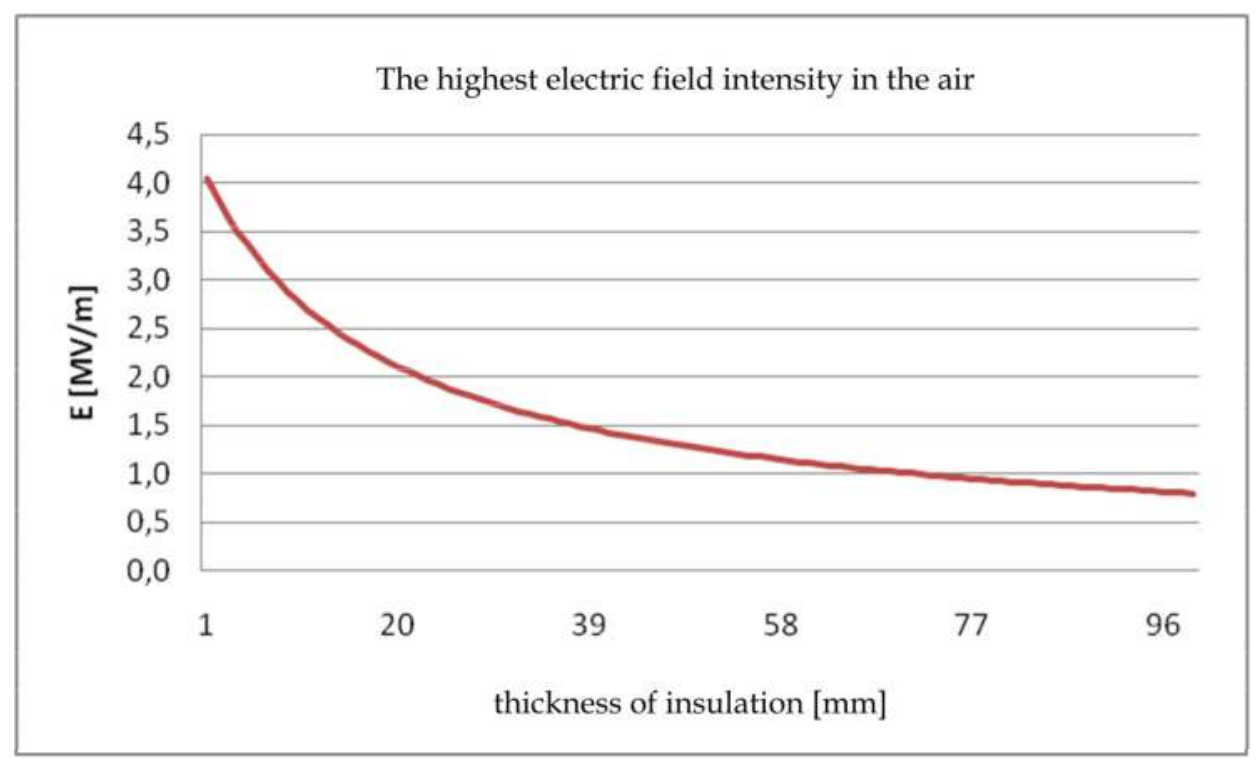

Figure 7. The highest electric field intensity in air 
The highest electric field intensity on the edge of the insulation for different values of relative permittivity

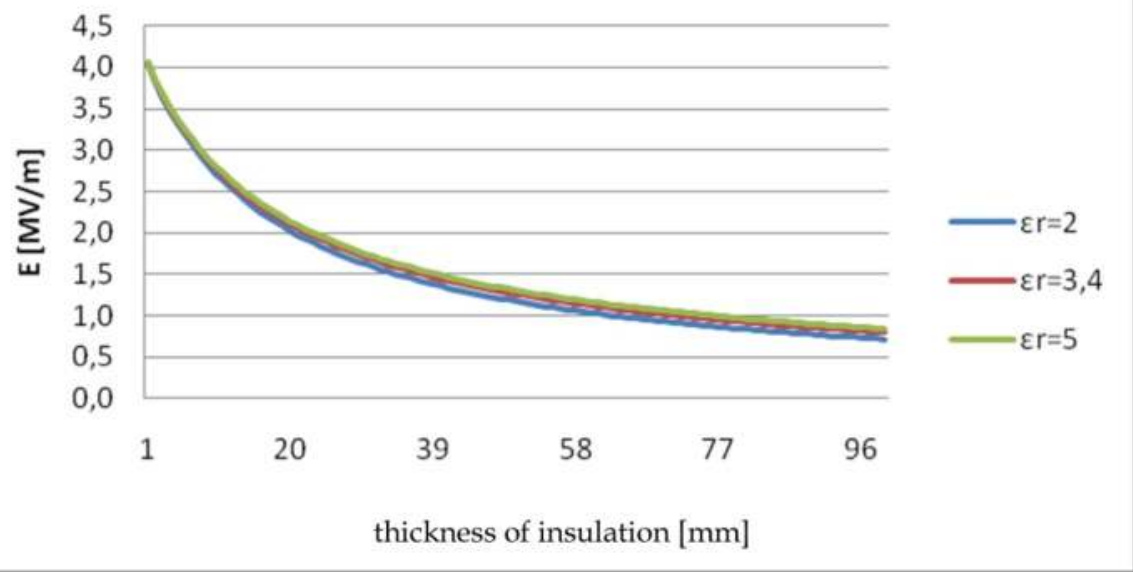

Figure 8. The highest field intensity on the edge of the insulation for different values of relative permittivity

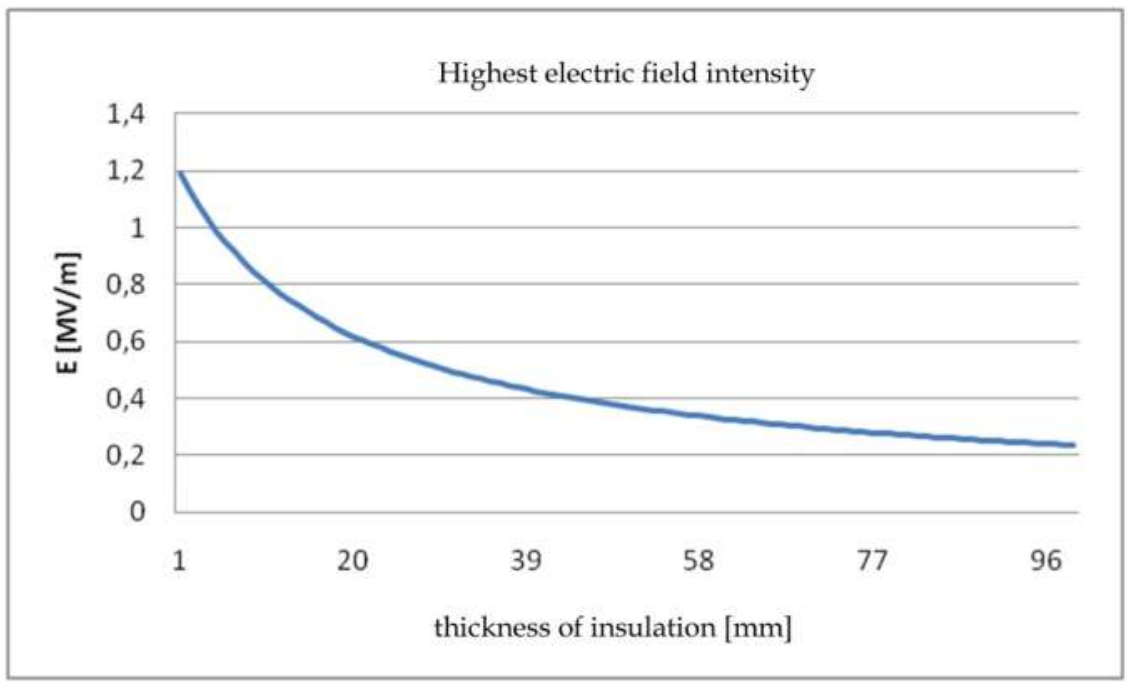

Figure 9. The highest electric field intensity on the edge of the conductor as the function of insulation thickness 


\section{The mechanics of the PUAC 2150/490/65 power line}

Mechanical calculations showed that the proposed cable (figure 10) meets the requirements. With the calculation of the formed catenary we get the height at which the conductor needs to be over the ground (figure 11) and thus the input data to determine the environmental impact of power lines by means of non-ionizing radiation.

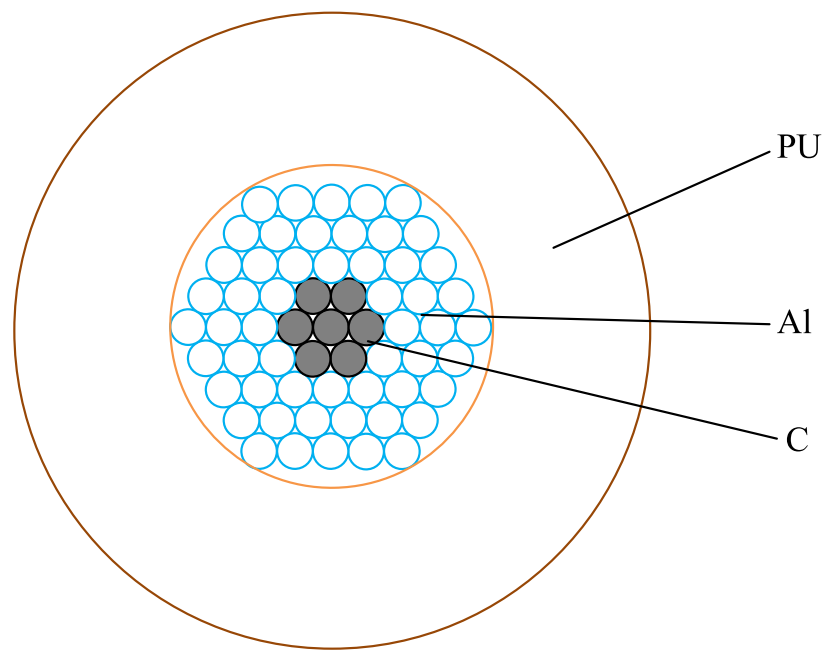

Figure 10. Cross section of the proposed covered conductor

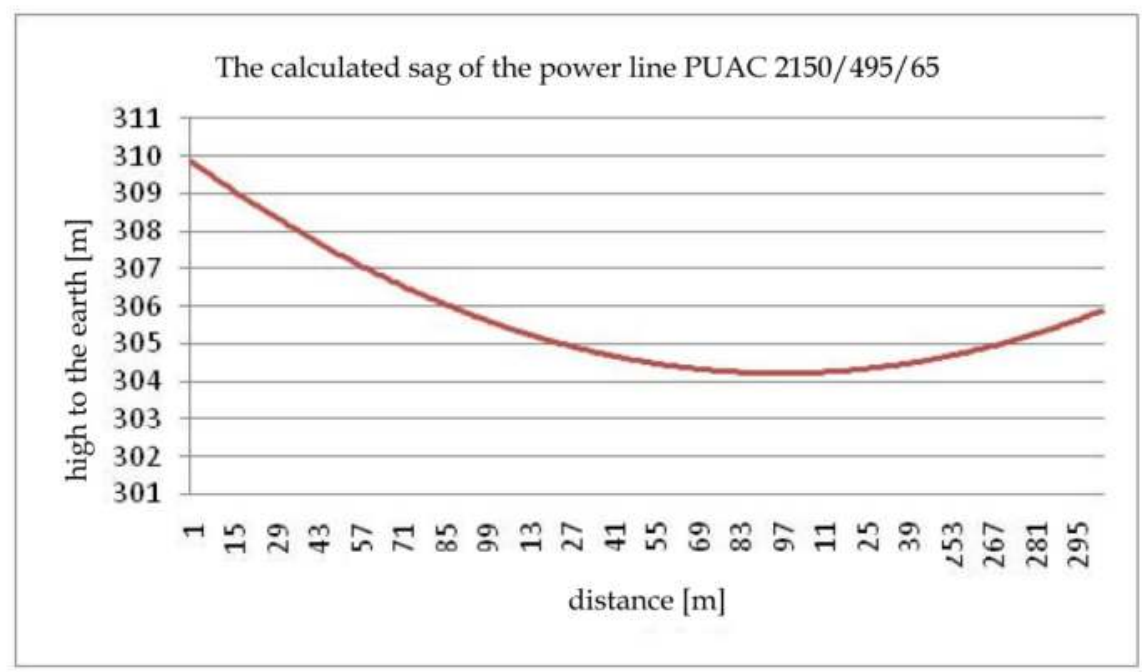

Figure 11. The calculated sag of the power line PUAC 2150/490/65 


\section{The electric field in the surrounding of a $400 \mathrm{kV}$ PUAC 2150/490/65 power line}

We deal with electric field in the surroundings of electrically charged bodies, for example in the vicinity of electric energy transmission lines, transmission antennas of telecommunications equipment. Electric fields are everywhere, where electric charge is present. Every electric conductor under voltage creates an electric field around itself. The field exists even when no current is flowing through the conductor, so even when the power line is not laden with users. The higher the voltage is the greater the electric field. Electric fields have the highest intensity close to the source and decrease very rapidly with distance. Metal shields them very well, but other material weaken it as well. The intensity of electric fields of power lines is greatly reduced by walls, buildings and trees. The electric fields of underground cables are also reduced by the soil.

We have determined that with the use of insulation made from polyurethane we can reduce the electric field intensity on the surface of covered conductors and that it is possible to operate at $400 \mathrm{kV}$. Due to the increased voltage it is necessary to examine the impact of such above ground power lines on the environment in accordance with our regulations.

\subsection{Electromagnetic radiation}

Exposure to electromagnetic radiations is not something new. It accompanies us from the very beginning of human existence. Here we think of natural sources of radiation. Another story is artificially generated sources, which are much stronger in intensity and more recently also increased in number. Man is now, unlike in the past, at home and at work, exposed to a complex mix of electric and magnetic fields.

The main sources of electric and magnetic fields of low frequencies $50 \mathrm{~Hz}$ are artificial sources of electromagnetic radiations, namely those caused by man, which are devices for transmitting and distributing electricity, electrical substations, and all devices that use electricity for their operation. The intensity of electromagnetic radiations emitted by artificial sources, in comparison with natural resources (the Earth's static magnetic field, electric field caused by the discharge in the atmosphere - lightning) is much higher. When an electrical device is plugged in, an electric field is generated in its surroundings. The higher the voltage, the stronger the electric field at a certain distance from the device. The electric field is present even when the device is not working because there is no need for the electric current to flow to create voltage. The magnetic field on the other hand requires a flow of electrons, so it occurs only when the device is plugged in and the current is flowing. Under these conditions both fields exist in the room. The greater the power consumption and thus the electric current, the stronger the magnetic field is.

\subsection{Evaluation of electromagnetic fields in the Slovenian legislation}

The Slovenian government adopted a regulation on electromagnetic radiations in the natural and living environment, which specifies the maximum allowed threshold of radiations. The regulation protects the most sensitive areas (EMR protection zone I, which 
includes living environment, schools, kindergartens, hospitals) with an additional preventive factor.

These areas demand increased protection against radiation therefore they are subject to ten times more severe limitations than in the European Union. For EMR protection zone II (areas with no residential building), the restrictions for magnetic fields are the same as in the European Union but for the intensity of the electric field two times higher values are allowed.

The maximum levels of radiation for networks with a frequency of $50 \mathrm{~Hz}$ are $500 \mathrm{~V} / \mathrm{m}$ and $10 \mu \mathrm{T}$ for EMR protection zones I and $10000 \mathrm{~V} / \mathrm{m}$ and $100 \mu \mathrm{T}$ for EMR protection zones II. Radiation with frequencies of $50 \mathrm{~Hz}$ includes electromagnetic fields from distribution substations, over ground and underground power lines, high voltage transformers and others. This is described under the Slovenian Regulation (2nd paragraph of article 2). At this frequency we distinguish two fields:

- The electric field, which is described with the effective value of the electric field intensity $E[\mathrm{~V} / \mathrm{m}]$ and depends on the voltage of the radiation source or the element

- The magnetic field, which is described with the Magnetic flux density $B[T]$ which depends on the electric current passing through the source of radiation or the element.

When calculating the effects of electromagnetic radiation we have to consider the most unfavorable impact on nature that can occur in normal operations.

\subsection{Electric field intensity in the vicinity of an overhead power line}

For the straight infinitely long conductor we assume that the electric charge is evenly distributed over the whole surface (uniform linear charge density). The charge on such a conductor can be described with an infinite line charge, which in any given point of $\mathrm{T}(\mathrm{x}, \mathrm{y})$ (Fig. 12) leads to the following vector of electric field intensity:

$$
\vec{E}=\overrightarrow{1}_{\mathrm{r}} \cdot \frac{q_{+}}{2 \cdot \pi \cdot \varepsilon_{0}} \cdot \frac{1}{\left|\vec{r}_{+}\right|}
$$

Where:

$\overrightarrow{1}_{\mathrm{r}} \quad$ is the unit vector of distance,

$q_{+} \quad$ is the positive value of the line charge,

$\left|\vec{r}_{+}\right| \quad$ is the absolute value of the distance vector between the electric charge and the point of observation and

$\varepsilon_{0} \quad$ is the vacuum permittivity.

To calculate the electric field intensity of a conductor above a conductive surface we use the method of equivalent charges. Its main idea is the exchange of the surface charge near a conductive surface (in our case soil) with a charge opposite in sign but equal in quantity that is projected over a conductive surface.

$$
\left[q_{+}\right]=[C] \cdot[V],
$$


where:

$\left[q_{+}\right]$is the columnar vector of positive charge,

$[V]$ is the columnar vector of conductor potentials,

[C] is the square matrix of the capacitance.

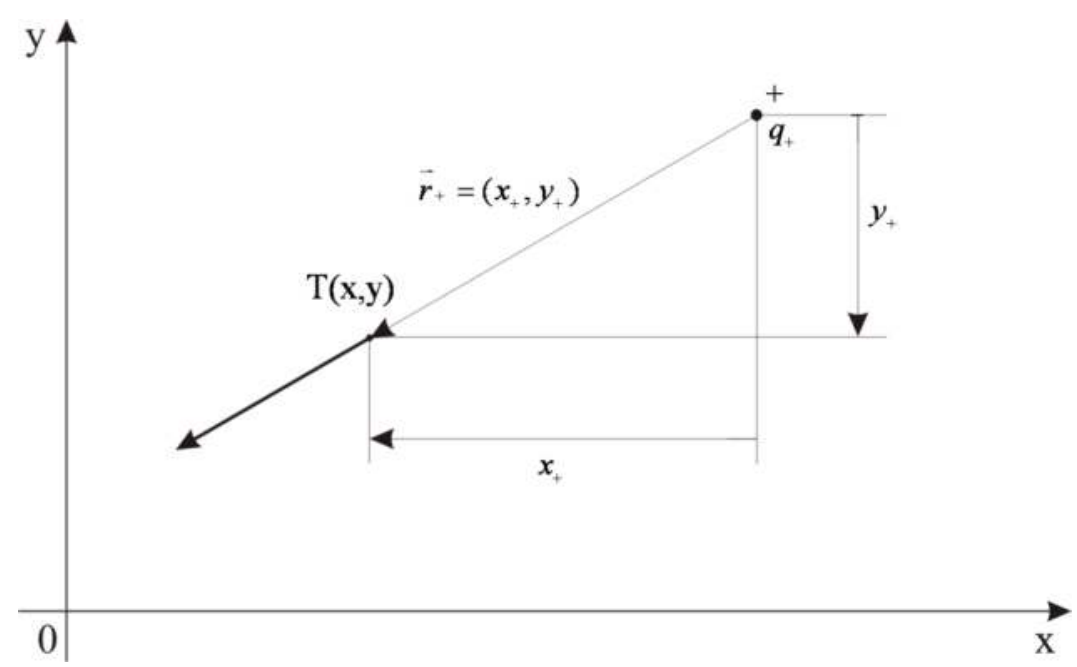

Figure 12. Electric field of a line charge

\subsubsection{Voltage on conductors}

To determine the electric field intensity we have to determine the charge on the phase conductors. These are obtained from the current values of the voltage taking into account the capacitance. In Figure 13 current value of tension on the $400 \mathrm{kV}$ overhead line are shown.

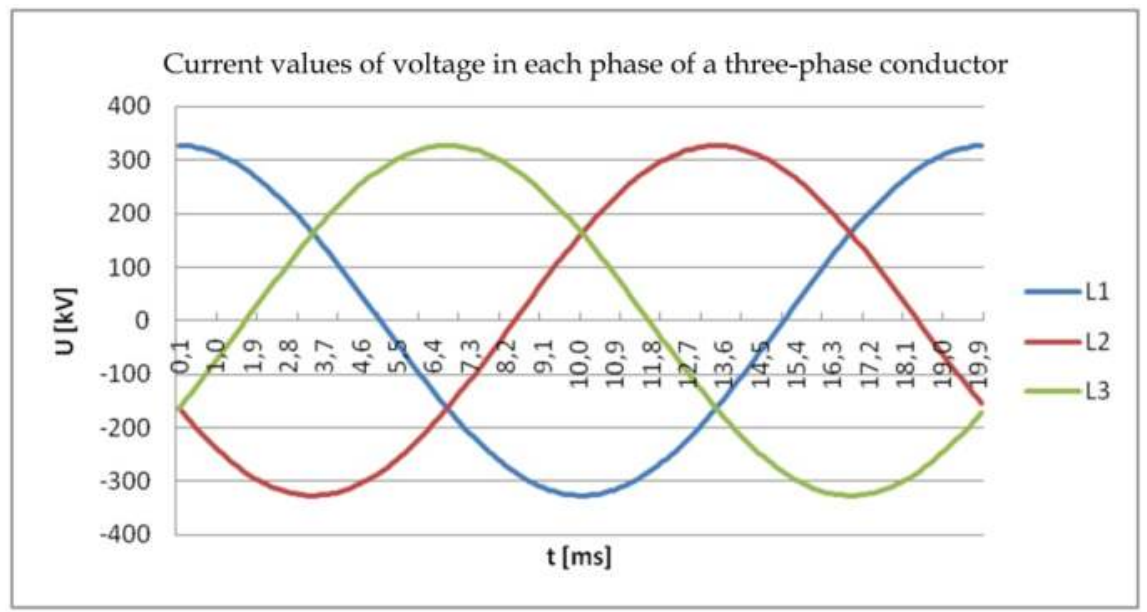

Figure 13. Current values of voltage in each phase of a three-phase conductor 


\subsubsection{Charge on conductors}

We get the matrix of capacitance $[C]$ by first determining the elements of the potential coefficients of the conductor $[p]$ (Tičar I., Zorič T., 2003):

$$
\begin{aligned}
& p_{\mathrm{ii}}=18 \cdot 10^{9} \cdot \ln \frac{H_{\mathrm{ii}}}{r} \quad\left[\frac{\mathrm{m}}{\mathrm{F}}\right] \\
& p_{\mathrm{ij}}=18 \cdot 10^{9} \cdot \ln \frac{H_{\mathrm{ij}}}{d_{\mathrm{ij}}} \quad\left[\frac{\mathrm{m}}{\mathrm{F}}\right],
\end{aligned}
$$

where:

$p_{\mathrm{ii}} \quad$ is the individual potential coefficient,

$p_{\mathrm{ij}} \quad$ is the mutual potential coefficient,

$\varepsilon_{0} \quad$ is the vacuum permittivity,

$d_{\text {ij }} \quad$ is the distance between multi-phase conductors,

$H_{\mathrm{ii}} \quad$ is the distance between the multi-phase conductors ant there mirror projections,

$H_{\mathrm{ij}} \quad$ is the distance between the multi-phase conductors and the mirror projections of other multi-phase conductors.

Distances established like that apply to bare conductors (line charge) in the air with a constant relative permittivity $\varepsilon_{0}$. In our case, where we are dealing with insulation around the conductors, the electric charge gathers on the edge of the insulation and we have to consider that the distance between conductors is reduced by the thickness of the insulation. So when we consider these reductions in distance and the designations on figure 14 we get the new:

- $\quad$ Individual« potential coefficient:

$$
p_{i i}=\frac{\frac{1}{\varepsilon_{\mathrm{r} 2}} \cdot \ln \frac{r_{2}}{r_{1}}+\ln \frac{H_{i i}}{r_{2}}}{2 \cdot \pi \cdot \varepsilon_{0}}
$$

- $\quad$ »Mutual« potential coefficient

$$
p_{i j}=\frac{\frac{1}{\varepsilon_{r 2}} \cdot \ln \frac{r_{2}}{r_{1}}+\ln \frac{H_{i j}}{d}}{2 \cdot \pi \cdot \varepsilon_{0}}
$$

We deal with three potential of conductors, four line charges and nine potential coefficients, which we can combine into a matrix.

$$
\left[\begin{array}{c}
V_{\mathrm{L} 1} \\
V_{\mathrm{L} 2} \\
V_{\mathrm{L} 3}
\end{array}\right]=\left[\begin{array}{lll}
p_{\mathrm{L} 1 \mathrm{~L} 1} & p_{\mathrm{L} 1 \mathrm{~L} 2} & p_{\mathrm{L} 1 \mathrm{~L} 3} \\
p_{\mathrm{L} 2 \mathrm{~L} 1} & p_{\mathrm{L} 2 \mathrm{~L} 2} & p_{\mathrm{L} 2 \mathrm{~L} 3} \\
p_{\mathrm{L} 3 \mathrm{~L} 1} & p_{\mathrm{L} 3 \mathrm{~L} 2} & p_{\mathrm{L} 3 \mathrm{~L} 3}
\end{array}\right] \cdot\left[\begin{array}{c}
q_{\mathrm{L} 1} \\
q_{\mathrm{L} 2} \\
q_{\mathrm{L} 3}
\end{array}\right]
$$




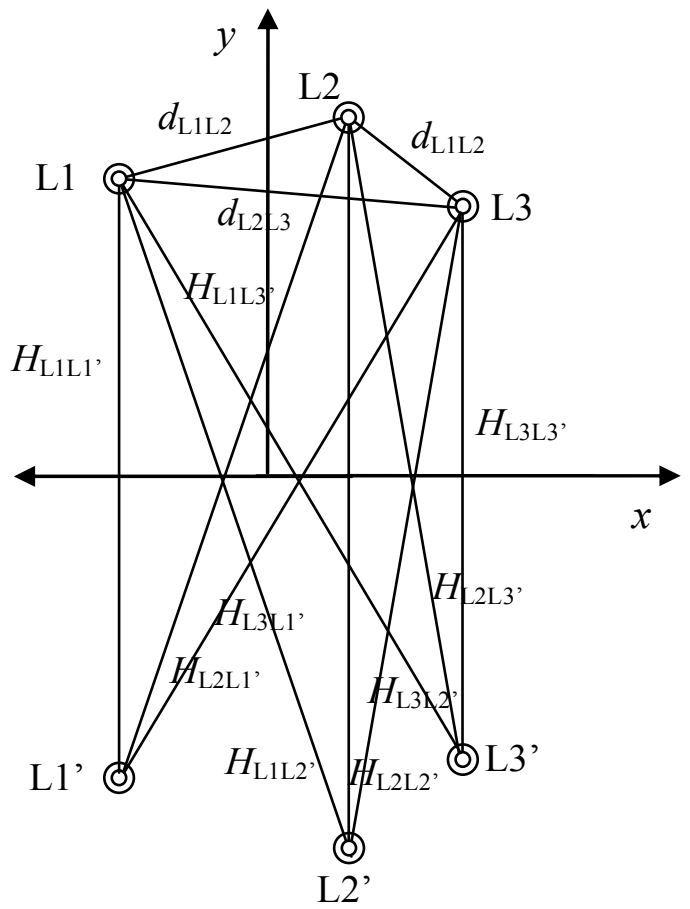

Figure 14. Mirror projections over the conductive surface plane

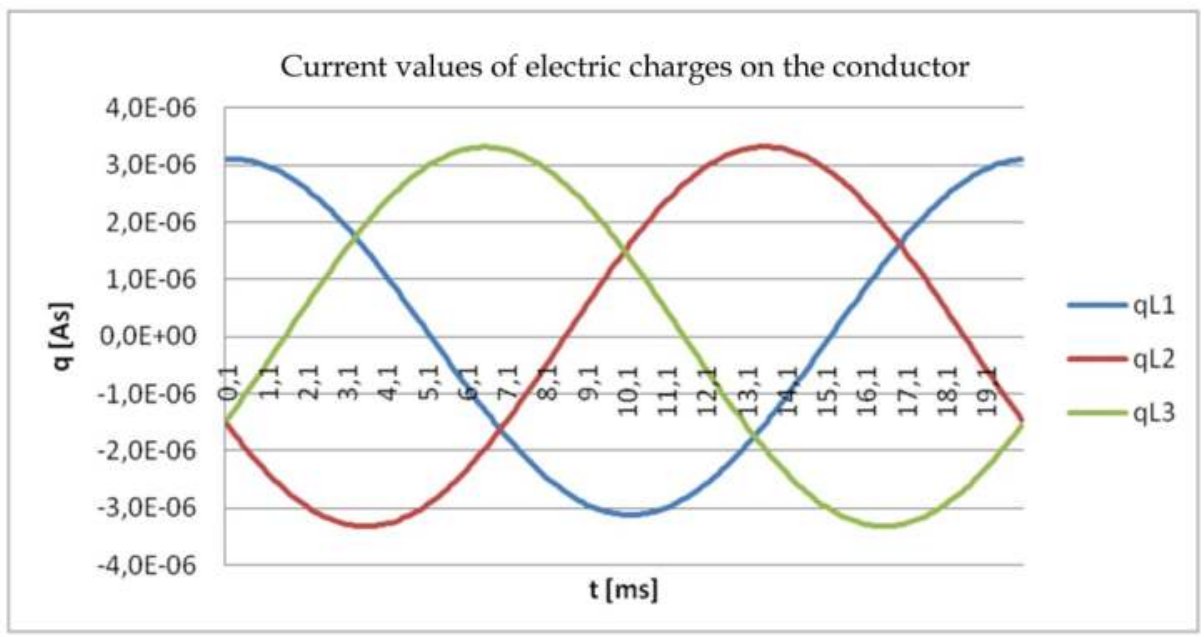

Figure 15. Current values of electric charge on the conductor 
From the equation $[C]=[p]^{-1}$ and by considering the geometry on figure 15 we get the current value of the electric charge on the conductors:

$$
[q]=[p]^{-1} \cdot[U]
$$

\subsubsection{Electric field intensity}

With the current values of electric charge on the conductor we calculated the components of the electric field intensity that exists because of the charge on all three phases.

We get the greatest electrical field intensity in the substance 2 at a radius $r_{2}$ (figure 4):

$$
E_{2 \max }=\frac{q}{2 \cdot \pi \cdot \varepsilon_{0} \cdot \varepsilon_{\mathrm{r} 2}} \cdot \frac{1}{r_{2}}=\frac{U \cdot \frac{1}{r_{2}}}{\varepsilon_{\mathrm{r} 2} \cdot\left(\frac{1}{\varepsilon_{\mathrm{r} 1}} \cdot \ln \frac{r_{2}}{r_{1}}+\frac{1}{\varepsilon_{\mathrm{r} 2}} \cdot \ln \frac{r_{3}}{r_{2}}\right)}
$$

We calculated the electric field intensity in several points of the space around the conductor. The points were selected at the edge of the insulation (at the radius $r_{2}$ ) of the multi-phase conductors. The radius was chosen so that the distance to the neighbouring conductors was as small as possible. As seen in figure 5 , the point for the phase L1 is at $(4.6785 ; 27.9785)$, for the phase L2 at $(3.9215 ; 30.9785)$ and for the phase L3 at(5.4785; 25.0215). We got the electric field intensity at the edge of the insulation for each individual phase conductor (figure 16, figure 17 and figure 18) with vector addition of the contribution of all the electric charges (equation 23). The geometric sum of the current values (the current value of the electric field intensity) is a periodic quantity, but not a sinus one.

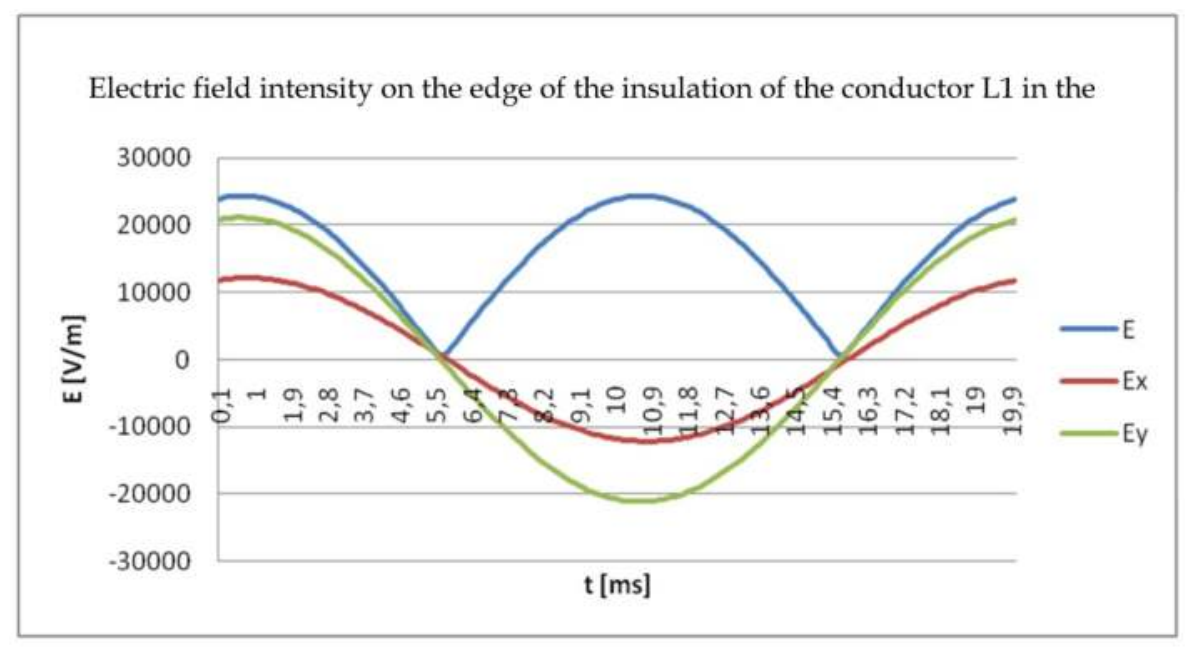

Figure 16. Electric field intensity on the edge of the insulation of the conductor L1 in the point (-4.6785; 27.9785) 
The electric field intensity on the edge of the insulation of the conductor L2 in the point $(3.9215 ; 30.9785)$

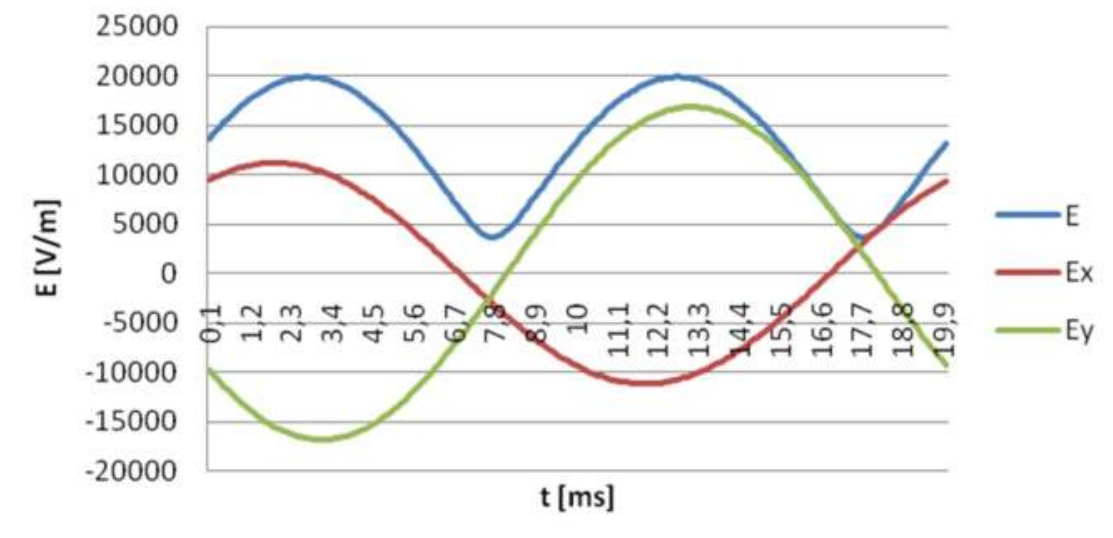

Figure 17. The electric field intensity on the edge of the insulation of the conductor L2

The electric field intensity on the edge of the insulation of the conductor L3 in the point $(5.4785 ; 25.0215)$

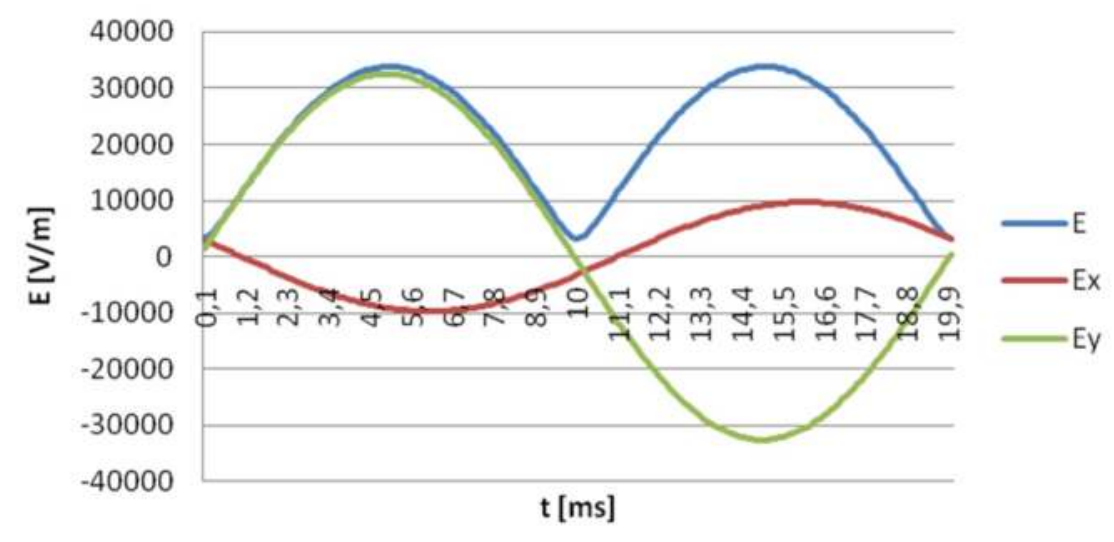

Figure 18. The electric field intensity on the edge of the insulation of the conductor L3 
We get the effective value of the electric field intensity by summing over the whole period. By definition, the effective value of the periodic quantity is the one which makes the same effect as the corresponding one-way quantity. In our case the effective value of the electric field intensity is as follows.

$$
E_{\mathrm{ef}}=\frac{1}{T} \cdot \int_{0}^{T} E^{2}(t) \cdot \mathrm{d} t
$$

here:

E ef is the effective value of the electric field intensity,

$T$ is the period,

E is the vector sum of all the contributing charges.

\subsubsection{The electric field intensity on the edge of the insulation}

The highest current value of the electric field intensity in the point $(-4.6785 ; 27.9785)-$ on the edge of the insulation of the conductor L1 is $24.366 \mathrm{e}+003 \mathrm{~V} / \mathrm{m}$ with the effective value of 17.235e+003 V/m.

The highest current value of the electric field intensity in the point $(3.9215 ; 30.9785)$ - on the edge of the insulation of the conductor L2 is $19.865 \mathrm{e}+003 \mathrm{~V} / \mathrm{m}$ with the effective value of $14.287 \mathrm{e}+003 \mathrm{~V} / \mathrm{m}$.

The highest current value of the electric field intensity in the point $(5.4785 ; 25.0215)$ - on the edge of the insulation of the conductor L3 je $33.813 \mathrm{e}+003 \mathrm{~V} / \mathrm{m}$ with the effective value of $24.023 \mathrm{e}+003 \mathrm{~V} / \mathrm{m}$.

From the calculations and figures, we see that the electrical field intensity at the edge of the insulation of any of these three conductors does not exceed the critical dielectric strength of air.

\subsubsection{The electric field strength perpendicular to the bisector of the span at the point of the} maximum sag

In the end we examine the consistency of the over ground $400 \mathrm{kV}$ power lines that use covered conductors with the Regulation. We have examined the electric field strength perpendicular to the bisector of the span at the point of the maximum sag, 1 meter above the ground. We use the vector addition in each point, to add the contributions of all phase conductors and their mirror images together. We did this in the same manner as we determined the electrical field intensity at the edge of the insulation of each individual phase conductor. We recorded the highest value of the electric field intensity at each point in the time of one period. We then determined the effective value in accordance with the equation (31). We calculated the points within a distance of 100 meters left and right from the bisector of the overhead power line in steps of $1 \mathrm{~m}$. The results are shown in figure 19. 
$\mathrm{E}_{\max }$ and $\mathrm{E}_{\mathrm{ef}}$ in a distance from the bisector of the transmission tower at a height of 1 meter above the ground

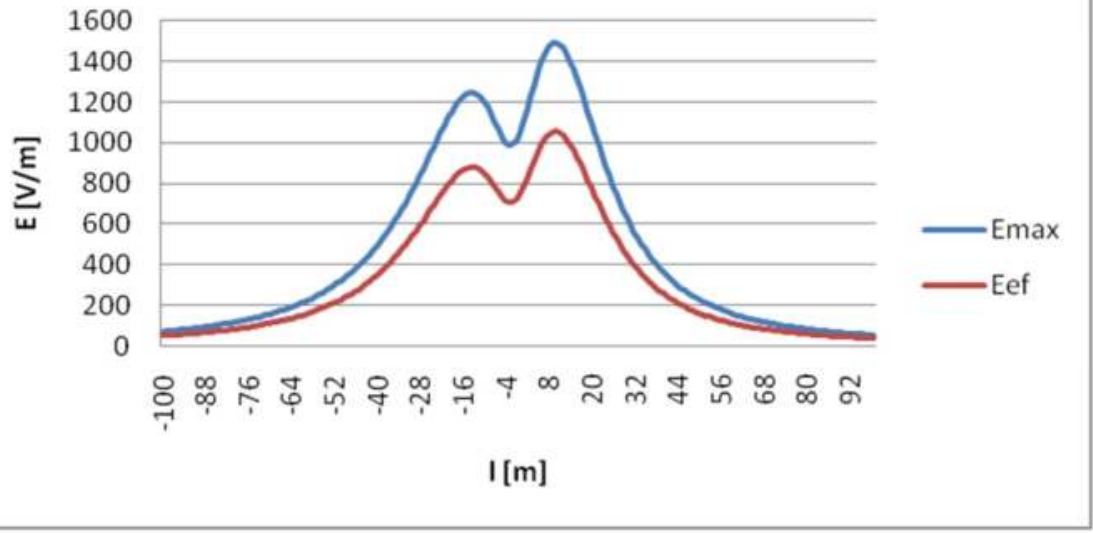

Figure 19. The electrical field intensity perpendicular to the bisector of the span in the point of the greatest sag.

The value of the electric field intensity falls under the permitted limit of the regulation at a distance of $30 \mathrm{~m}$ away from the bisector of the power line.

\section{The calculation of the electric field intensity with the finite element method}

The planned covered conductor does not float in the air by itself, but is mounted in a threephase electric system and hanged on a steel construction. Because of that, an analytical approach is not sufficient and the approximate results have to be checked with the finite element method.

\subsection{Calculation of the electric field intensity at the edge of the insulation of the conductor}

Based on the measurements on figure 5, we calculated the maximum electric field intensity of the phase L1, using the computer program ELEFANT ${ }^{\circledR}$. For the basic harmonic current this holds true when the voltage of the phase L1 is $326 \mathrm{kV}$ and $163 \mathrm{kV}$ for the phase L2 and L3. The phase to phase voltage from phase L1 to the other two phases is then at an amplitude value of $400 \mathrm{kV}-565.69 \mathrm{kV}$. From figure 20 you can see that the electric field intensity does not exceed the value of $0.1 \mathrm{MV} / \mathrm{m}$, which is less than what we got from our analytical calculation (equation 22). 

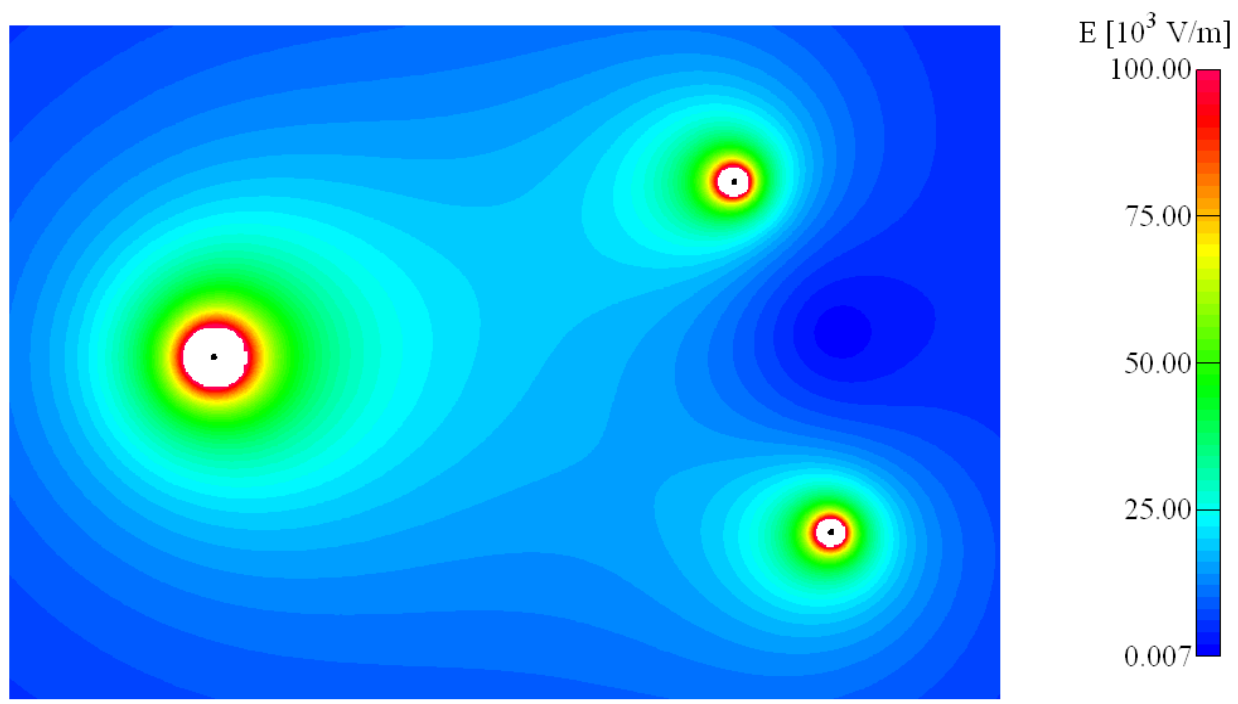

Figure 20. The electric field intensity calculated with the computer program ELEFANT ${ }^{\circledR}$

\subsection{Calculation of the electric field intensity perpendicular to the conductor}

As a result, a figure is shown that depicts the calculation of the effective value of the electric field intensity perpendicular to the conductor in the point of the greatest sag (figure 21). The calculation results of the programs Matlab and Elefant are compared (figure 22).

In comparison, we see that both calculations give approximately the same result and that using both methods gives a value that is under the maximum allowed effective value permitted by the law.

With the use of the computer program we calculated the phase voltage of line conductors as a function of time (in a time period of $20 \mathrm{~ms}$ ).

We calculated the potential coefficients of the capacitance (the inverse value of the matrix of potential coefficients), based on the geometry (arrangement of conductors and the insulation on them). We also calculated the current electric charge on the phase conductors based on the current values of voltage. With the known charges we calculated all three vectors of the electric field intensity, which are caused by the current values of charge on the individual line conductors in the point of interest. In the point of interest the current values of the vectors were added together, to get the total vector of electric field intensity. This total vector is dependent upon the three current values of charge on the line conductors. The resulting electric field intensity is not sinusoid quantity (figure 18) but it is a periodic quantity. We calculate the effective value in accordance with equation (31). 


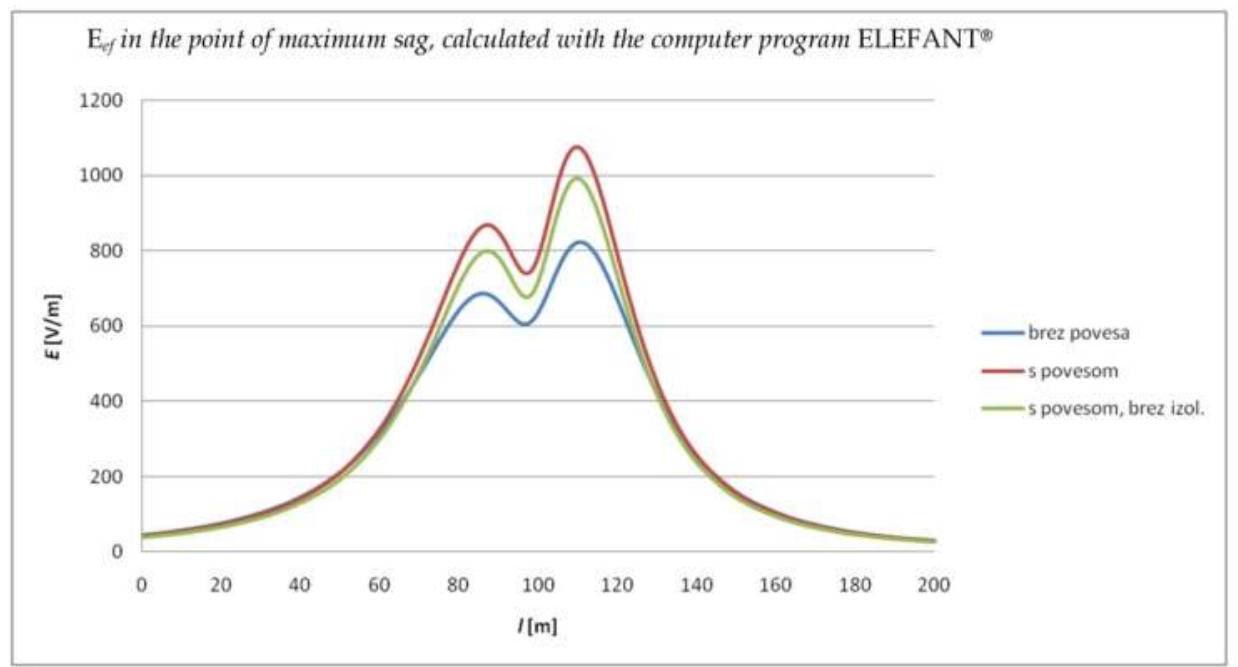

Figure 21. Eef in the point of maximum sag, calculated with the computer program ELEFANT ${ }^{\circledR}$

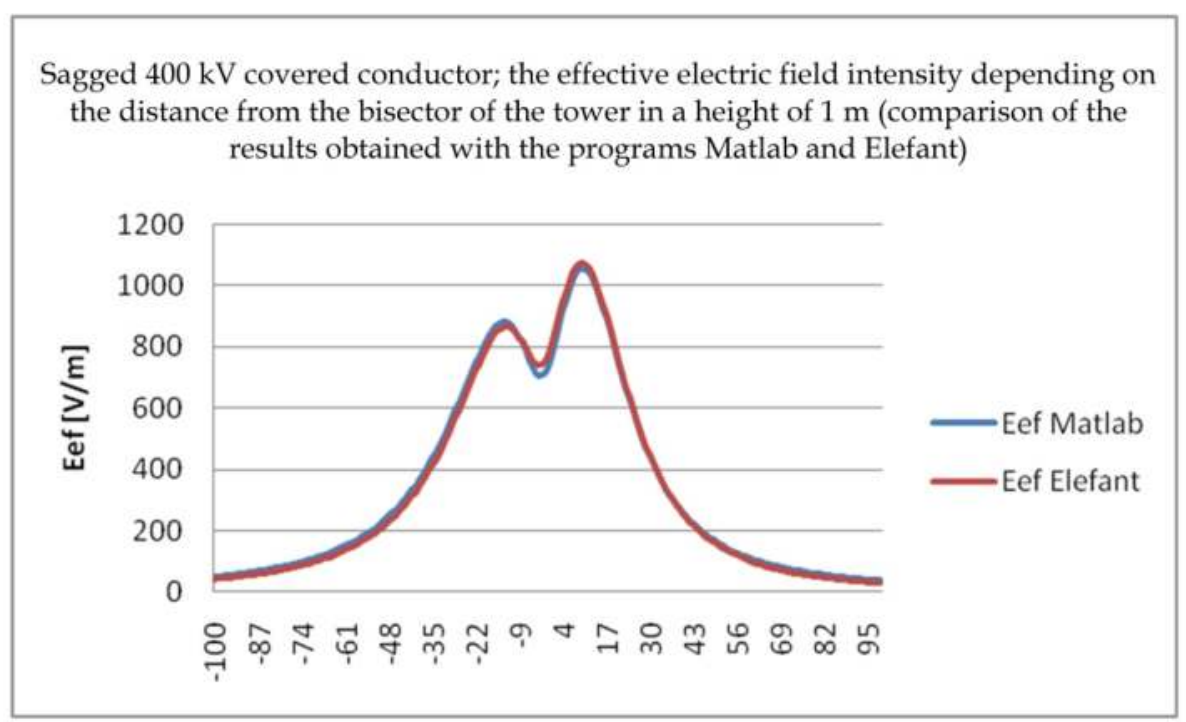

Figure 22. Comparison of Eef perpendicular to the conductors in the point of maximum sag calculated with the programs Matlab and Elefant. 
Figure 22 shows the calculation for points $1 \mathrm{~m}$ above the ground transverse to the power line in the area of the maximum sag of the cable using the analytical method and the finite element method.

\section{Conclusion}

The Slovenian power system designers tend to reduce the number of voltage levels. In the future, only four levels will probably exist: $0.4 ; 20 ; 110$ and $400 \mathrm{kV}$. The $10 \mathrm{kV}$ levels are in the middle of the range and are present only in large towns (Ljubljana, Maribor). One of the major problems is abandonment of the $220 \mathrm{kV}$ voltage level in the transmission network. The designers are thinking about preservation of the $220 \mathrm{kV}$ power line platforms and the transition to $400 \mathrm{kV}$ conductors. The simplest solution seems to be the erection of new overhead power lines, yet this would involve substantial funds and new permissions. The proposition is the use of covered conductors. The purpose of this chapter was to determine whether it is possible to use the existing platforms and transmission towers of the $220 \mathrm{kV}$ power lines with the new $400 \mathrm{kV}$ conductors. We proposed a covered conductor with a carbon fibber core and a conductive layer made from aluminium, surrounded by in insulation made from polyurethane. The insulation thickness was calculated as the double insulation of the conductor was made from two layers, the one being polyurethane and the other air. We determined a radius at which the electric field intensity at the edge of the insulation is not high enough to cause breakdown of the surrounding air (the electric field intensity has to be lower than the dielectric strength of air). For the reduction of weight of the conductor we assume that we can replace the steel core with a core made from carbon fibbers.

We attempt to calculate the electric field intensity in the air (at the edge of the insulation) with the following values. For the radius of the conductor we take the radius of the current $220 \mathrm{kV}$ conductor, which is $15.3 \mathrm{~mm}$. For the thickness of the insulation we use $15 \mathrm{~mm}$ and its dielectric strength $\varepsilon_{\mathrm{r}}=3.4$. For the voltage we use $400 \mathrm{kV}$. The result we get with these values is $2.39 \mathrm{MV} / \mathrm{m}$, which is less than the dielectric strength of air.

The proposed conductor will have a core made from carbon, a conductive layer made from aluminium and the insulation made from polyurethane. According to the usual labelling of conductors we named the suggested conductor PUAC 2150/490/65 $\mathrm{mm}^{2}$. Here $2150 \mathrm{~mm}^{2}$ stands for the cross section of the polyurethane mantel, $490 \mathrm{~mm}^{2}$ for the aluminium and 65 $\mathrm{mm}^{2}$ for the core made form carbon fibber. The electrical resistance of the covered conductor doesn't change in comparison with a normal conductor and is $R=0.0592 \Omega / \mathrm{km}$. Likewise the dielectric strength of the insulation mantle does not affect the electrical reactance of the conductor, which is $=0,414 \Omega / \mathrm{km}$. For the proposed conductor PUAC $2150 / 490 / 65 \mathrm{~mm}^{2}$ with a $15 \mathrm{~mm}$ thick insulation layer made from polyurethane $\left(\varepsilon_{\mathrm{r}}=3.4\right)$ the capacitance is $C=12.6 \mathrm{nF} / \mathrm{km}$.

The over ground conductors are used to transfer electricity between two points and they lead through various parts of the area. We calculated the mechanical properties of the proposed cable and the sag in the middle of the imaginary span and over obstacles. With 
this data we calculated the impact of non-ionizing radiation that over ground lines exert on the environment.

The installation of an over ground power line is disruptive to the environment. The frequency that we use for the transfer of electricity in the distribution network is $50 \mathrm{~Hz}$, and it causes a magnetic field with the same frequency. This electromagnetic field falls in to the category of low frequency fields. As negotiated at an international level it actually belongs to electromagnetic fields with very low frequencies (ELFF), with frequencies ranging from 30-300 $\mathrm{Hz}$. This is the range at which we talk about electric and magnetic fields separately, instead of electromagnetic fields. The electric field is the result of electric charge on the conductor and in the ground. It is also indirectly linked to the voltage between conductor and ground, the higher the voltage the higher the electric field is. If we look at the limit values that are determined in the Slovenian legislation the electric field is more problematic than the magnetic field. We calculated the electric field intensity in the critical points, and found that it is smaller than the value that is allowed under the regulation about non-ionizing radiation. We also calculated the electric field intensity perpendicular to the axis of the over ground conductor in the point of the greatest sag. It fall on the specified value determined by the regulation for new buildings in a distance of $75 \mathrm{~m}$ from the axis of the over ground conductor. We checked the results with a calculation using the finite element method.

We found that the proposed covered conductor does not need a wider corridor as it is already set for the $220 \mathrm{kV}$ overhead power line with bare conductors and allows the transfer of energy at $400 \mathrm{kV}$.

As future work we propose the construction of a prototype of such a conductor, laboratory experiment of these theoretical calculations and an economic analysis: cost of new conductors and the replacement of these on the existing transmission towers - the price of building the new above ground power line with all the necessary permits.

\section{Author details}

Žiga Voršič

University of Maribor, Slovenia

\section{References}

R.J. Bacha, GPU/PENELEC Compact $115 \mathrm{kV}$ Covered Conductor Study, Minutes of the Meeting - Pennsylvania Electric Association, Engineering Section, 1981

Manfred Beyer, Wolfram Boeck, Klaus Möller, Walter Zaengl, Hochspannungstechnik, Theoretische und praktische Grundlagen; Springer-Verlag 1986.

Ray Elford: Covered Conductors - making the right choice, Electrical engineer, februar 1995 Michèle Gaudry, Francis Chore, Claude Hardy, Elias Ghannoum: Increasing the ampacity of overhead lines using homogeneous compact conductors, Pariz 1998

Damjan Miklavčič: Vpliv elektromagnetnih polj na biološk esisteme, Zbornik 2, Konference slovenskega komiteja CIGRE, Maribor, 7. - 9. junij 1995: 445 452 
Jože Pihler, Igor Tičar: Design of systems of covered overhead conductors by means of electric field calculation, IEEE, April 2005

Hans Prinz, Hochspannungsfelder, R. Oldenbourg Verlag, Munchen 1969

Heine P., Pitkänen J, Lehtonen M, Sag Characteristics of Covered Conductor Feeders, 38th International Universities Power Engineering Conference, UPEC 2003, Thessaloniki, Greece, September 2003

Recueil CEI / IEC, Symboleslittérauxet conventions, Zajednica JEK, Beograd 1986.

F. Sato, H. Ebiko: Development of a low sag aluminum conductor Carbon fiber reinforced for transmission lines, Pariz 2002

Janko Šarman, Električno in magnetnopolje v okolici visokonapetostnih daljnovodov 110,220 in $400 \mathrm{kV}$, diplomska naloga, UM FERI, 1999.

Sašo Škorjanc: Izračunelektromagnetnegapoljavodnikov,diplomskodelo, UM FERI, Maribor 2005

Simon Tajnšek, Magistrska naloga: Nov sistem nadzemnih vodov s polizoliranimi vodniki, UM Fakulteta za elektrotehniko, računalništvo in informatiko, Maribor, december 2005

Igor Tičar, Oszkar Biro, Kurt Preis, Uporaba 2D in 3D metode končnih elementov v bielektromagnetnih raziskavah, Tretja konferenca slovenskih elektroenergetikov, Nova Gorica, 3.-5.junij 1997.

Igor Tičar, Tine Zorič, Osnove elektrotehnike 1. zvezek Elektrostatična in tokovna polja, Univerza v Mariboru, FERI, Maribor 2003

M. J. Tunstall, S.P. Hoffmann: Maximising the ratings of national grid's existing transmission lines using high temperature, low sag conductor, Pariz 2000

Stane Vižintin, Tadeja Babnik, Franc Jakl: Možnost uporabe sodobnih tehnologij vodnikov pri novi generaciji $400 \mathrm{kV}$ nadzemnih vodov, Elektroinštitut Milan Vidmar, Ljubljana, januar 2007

Jože Voršič, Jože Pihler: Tehnika visokih napetosti in velikih tokov, UM FERI, 2005

Žlahtič, Franc, Cestnik, Breda, Grajfoner, Slavko, Jakl, Franc. Vpliv uredbe o elektromagnetnem sevanju na parametre 110 in $400 \mathrm{kV}$ daljnovodov $=$ Effects of the newly enforced law controlling electromagnetic radiation on parameters of 110 and 400 $\mathrm{kV}$ power lines. $\mathrm{V}$ :

http://www.eles.si/za-poslovne-uporabnike/razvoj-in-uporaba-prenosnegaomrezja/strategija-razvoja-elektroenergetskega-sistema-rs.aspx

Pravilnik o tehničnih normativih za graditev nadzemnih elektroenergetskih vodov $\mathrm{z}$ nazivno napetostjo od $1 \mathrm{kV}$ do $400 \mathrm{kV}$, Ljubljana 2009

SIST EN 50341-3-21; Nadzemni električni vodi za izmenične napetosti nad 45 kV, februar 2009

Terminološkakomisija (urednik Anton Ogorelec), Slovenski elektrotehniški slovar, Področje elektroenergetika, Sloko CIGRÉ, Ljubljana 1996.

Tretja konferenca slovenskih elektroenergetikov, Nova Gorica, 3.-5.junija, 1997. Zbornik. Ljubljana: Slovenski komite Mednarodne conference za velike elektroenergetske sisteme, 1997, str. 36/23-28

Uredba o elektromagnetnem sevanju v naravnem in življenjskem okolju, Uradni list RS, št. 70/1996 